\title{
PERANCANGAN REAKTOR BIOGAS DI UPTD PASAR TERNAK PALANGKI
}

\author{
Ashadi Rizki Zumaro', Yaumal Arbi \\ Teknik Lingkungan, Sekolah Tinggi Teknologi Industri Padang \\ email : ${ }^{1}$ rizkizumaro@gmail.com, ${ }^{2}$ yaumalarbi@sttind.ac.id
}

\begin{abstract}
ABSTRAK
Sektor peternakan menyumbang 37\% metana dan 65\% nitro oksida (lebih kuat dari CO2), gas metana adalah sebuah gas yang dihasilkan dari proses pencernaan hewan dapat mencapai 86 juta ton/tahun dan metana yang terlepas dari kotoran hewan mencapai 18 juta ton/tahun. (Laporan LIVESTOCKS, FAO tahun 2007). Apabila disederhanakan, tulisan diatas menerangkan bahwa limbah kotoran yang dihasilkan dari satu ekor sapi dewasa ikut memberikan andil terhadap pemanasan global (Global Warming) hal itu disebabkan tidak adanya perlakuan yang tepat dan kotoran disimpan di area terbuka sehingga terkena sinar matahari langsung akibatnya gas metan yang dihasilkan dari kotoran hewan menguap. Salah satu sumber dari kotoran hewan yang ada di Indonesia adalah pasar ternak. UPTD Pasar Ternak Palangki merupakan pasar ternak terbesar seSumatera Barat, Pasar Ternak ini berada di Nagari Palangki, Kecamatan IV Nagari Kabupaten Sijunjung, rata-rata setiap tahun $(2011$ - 2016) hewan yang masuk ke UPTD ini mencapai 22215 ekor, salah satu solusi teknologi untuk mengatasi kotoran hewan adalah biogas.
\end{abstract}

Kata Kunci : Masalah Lingkungan,UPTD,Bioga

\section{PENDAHULUAN}

Permintaan kebutuhan Bahan Bakar Minyak (BBM) di Indonesia baik itu untuk keperluan industri, transportasi dan rumah tangga dari tahun ketahun semakin meningkat. Menyebabkan ketersediaan bahan bakar menjadi terbatas, atau harga menjadi melambung. Pertumbuhan penduduk,juga menyebabkan sumber daya alam yang tersedia berkurang, seperti bahan bakar minyak (BBM), eksploitasi sumber daya alam, khususnya minyak, yang telah membesar-besarkan ancaman bagi keselamatan manusia dan lingkungan itu sendiri. Hal lain yang banyak dikhawatirkan orang bahwa jumlah cadangan minyak yang menurun dari hari ke hari dan terancam habis. Karena itu perlu mencoba untuk mencari energi alternatif untuk menghemat cadangan minyak yang ada saat ini. Biogas adalah salah satu energi yang dapat dikembangkan dengan memberikan cukup bahan baku yang tersedia dan Ramah lingkungan. masalah dapat diatasi dengan kebutuhan energi menggunakan sumber energi terbaru yang relatif mudah didapat, dan biaya operasional yang rendah, tidak mengakibatkan masalah limbah. salah satunya yaitu dengan memanfaatkan kotoran sapi sebagai biogas.

Biogas merupakan salah satu solusi teknologi energi untuk mengatasi kesulitan masyarakat akibat kenaikan harga BBM, teknologi ini bisa segera diaplikasikan, terutama dikalangan masyarakat pedesaan yang memelihara hewan ternak sapi. Dalam rangka pemenuhan keperluan energi rumah tangga, khususnya di pedesaan, maka perlu dilakukan upaya yang sistematis untuk menerapkan berbagai alternatif energi yang layak bagi masyarakat. 
Disamping itu dengan memanfaatkan kotoran hewan dapat juga mengurangi pemanasan global karena Sektor peternakan menyumbang $37 \%$ metana dan $65 \%$ nitro oksida (lebih kuat dari CO2), gas metana adalah sebuah gas yang dihasilkan dari proses pencernaan hewan dapat mencapai 86 juta ton/tahun dan metana yang terlepas dari kotoran hewan mencapai 18 juta ton/tahun. (Laporan LIVESTOCKS, FAO tahun 2007)

Apabila disederhanakan tulisan diatas menerangkan bahwa limbah kotoran yang dihasilkan dari satu ekor sapi dewasa ikut memberikan andil terhadap pemanasan global (Global Warming) hal itu disebabkan tidak adanya perlakuan yang tepat dan kotoran disimpan di area terbuka sehingga terkena sinar matahari langsung akibatnya gas metan yang dihasilkan dari kotoran hewan menguap. Salah satu sumber dari kotoran hewan yang ada di Indonesia adalah pasar ternak.

UPTD Pasar Ternak Palangki merupakan pasar ternak terbesar seSumatera Barat Pasar Ternak ini berada di Nagari Palangki, Kecamatan IV Nagari Kabupaten Sijunjung. Lokasi Pasar Ternak berada dipinggir jalan raya Lintas Sumatera berjarak sekitar 10 kilometer dari Muaro Sijunjung ibukota Kabupaten Sijunjung, kurang lebih 100 kilometer dari kota Padang, ibukota Propinsi Sumatera Barat dan kurang lebih 110 kilometer dari gerbang selatan Propinsi Sumatera Barat. Lokasi ini memberi kemudahan bagi para pedagang baik dari luar Kabupaten Sijunjung maupun luar Propinsi Sumatera Barat untuk datang bertransaksi di Pasar Ternak Palangki. Pedagang ternak yang bertransaksi di Pasar Ternak Palangki antara lain berasal dari luar Propinsi Sumatera Barat ( Sumatera Selatan, Bengkulu, Jambi, Riau, Sumatera Utara, Aceh dan P. Jawa ) dan pedagang ternak yang berasal dari kabupaten/kota didalam Propinsi Sumatera Barat ( Dharmasraya,
Sawahlunto, Solok, Tanah datar, Payakumbuh, Padang panjang, Pariaman, Padang dan Sijunjung sendiri ).

Pasar Ternak Palangki berfungsi sebagai grosir bagi ternak ternak yang diperjual belikan. Umumnya ternak yang diperjual belikan di Pasar Ternak Palangki tidak untuk pemakai akhir ( dipotong untuk konsumsi ) tapi dibeli oleh pedagang ternak yang akan menjualnya kembali di tempat asalnya.

\section{METODOLOGI PENELITIAN}

\subsection{Jenis Penelitian}

Jenis Penelitian ini adalah penelitian pengembangan, menurut Undang-undang Republik Indonesia Nomor 18 Tahun 2002 Pengembangan adalah kegiatan ilmu pengetahuan dan teknologi yang bertujuan memanfaatkan kaidah dan teori ilmu pengetahuan yang telah terbukti kebenarannya untuk meningkatkan fungsi, manfaat, dan aplikasi ilmu pengetahuan dan teknologi yang telah ada, atau menghasilkan teknologi baru. Pengembangan secara umum berarti pola pertumbuhan, perubahan secara perlahan (evolution) dan perubahan secara bertahap.

Hasil Penelitian tidak perlu sebagai suatu penemuan baru, tetapi merupakan aplikasi baru dari penelitian yang telah ada.

\subsection{Lokasi Penelitian}

Penelitian ini akan dilakukan di UPTD Pasar Ternak Palangki Kabupaten Sijunjung.Waktu penelitian akan di laksanakan pada September 2016.

\subsection{Teknik Pengolahan dan Analisis Data}

Dibawah ini akan dijelaskan berbagai teknik pengolahan dan analisis data yang berkaitan dengan penelitian ini.

Prosedur Perancangan Biodigester ( Reaktor Biogas ) 


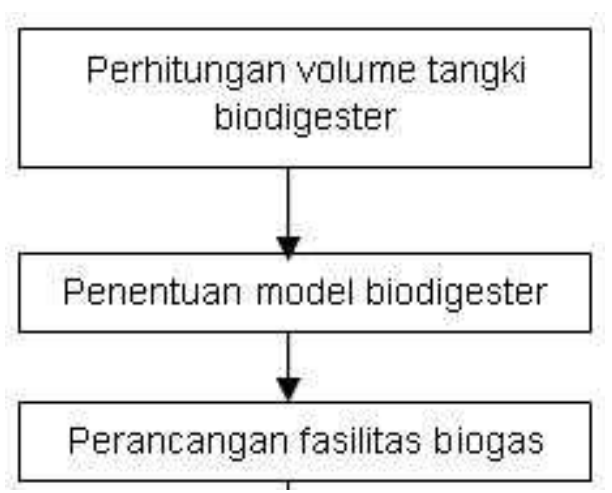

Urutan perancangan fasilitas biodigester dimulai dengan perhitungan volume biodigester, penentuan model biodigester, perancangan tangki penyimpan dan diakhiri dengan penentuan lokasi.

\section{A. Perhitungan Potensi Biogas}

Perhitungan ini menggunakan data-data:

Jumlah kotoran sapi $=\mathrm{n} \times 25 \mathrm{~kg} /$ hari

Untuk mendapatkan jumlah kotoran sapi perhari, digunakan persamaan, dimana $n$ adalah jumlah sapi (ekor), $25 \mathrm{~kg} / \mathrm{hari}$ adalah jumlah kotoran yang dihasilkan oleh 1 (satu) ekor sapi dalam sehari.

Untuk menentukan potensi biogas adalah dengan menggunakan rumus berikut ini :

Potensi Biogas $=$ Jumlah Kotoran Sapi $\mathrm{x}$ $0,04 \mathrm{~m}^{3}$

Potensi biogas dapat ditentukan dengan mengalikan jumlah kotoran sapi dengan 0,04 $\mathrm{m}^{3}$ ( Wahyuni,2011)

\section{B.Perhitungan Volume Biodigester}

Kotoran hewan yang telah diperoleh tadi harus ditambahkan air sebelum masuk biodigester agar bakteri dapat tumbuh dan berkembang dengan optimum. Perbandingan komposisi antara kotoran hewan dengan air adalah 1:1. Dengan demikian, jumlah air yang ditambahkan adalah:

Air yang harus ditambahkan $=1$ x Jumlah Kotoran Sapi
Hasil perhitungan di atas menunjukkan massa total larutan kotoran padat (mt). Waktu penyimpanan tergantung pada temperatur lingkungan dan temperatur biodigester. Dengan kondisi tropis seperti Indonesia, asumsi waktu penyimpanan adalah empat belas hari

Dari data-data perhitungan di atas, maka diperoleh volume larutan kotoran yang dihasilkan adalah sebesar:

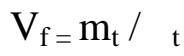

dengan $\rho t=$ massa jenis air $(1000 \mathrm{~kg} / \mathrm{m} 3)$.

Setelah volume larutan kotoran diketahui, maka volume biodigester dapat ditentukan dengan menggunakan persamaan:

$$
\mathrm{V}_{\mathrm{d}}=\mathrm{V}_{\mathrm{f} \cdot \mathrm{t}_{\mathrm{r}}}
$$

dengan $\operatorname{tr}=$ waktu penyimpanan di reaktor biogas.

\section{Penentuan Model Biodigester}

Penentuan model biodigester didasari oleh beberapa pertimbangan, yaitu:

1. Jenis tanah yang akan dipakai

2. Kebutuhan

3. Biaya

\section{Perancangan fasilitas biodigester}

Dapat ditentukan setelah desain atau model biodigaster selesai.

\section{HASIL DAN PEMBAHASAN}

Berdasarkan Hasil Pengamatan sebelumnya pada UPTD pasar ternak Palangki Kabupaten Sijunjung, didapatkan hasil pengamatan bahwa kotoran hewan di UPTD pasar ternak Palangki belum terkelola dengan baik, kotoran hewan yang di UPTD hanya ditumpuk kemudian dibakar bersamaan dengan sisa-sisa pakan ternak yang terbuang.

Dari penelitian yang telah dilakukan dalam menghitung jumlah energi atau jumlah potensi biogas, hal pertama yang harus diperhitungkan adalah berapa banyak jumlah bahan baku yang dihasilkan. Jumlah bahan baku ini akan menentukan 
berapa banyak potensi biogas yang dihasilkan dan volume alat pembentuk biogas tersebut. Jumlah bahan baku gas ini didapatkan dengan menjumlahkan kotoran yang dihasilkan pada jum'at sore sampai sabtu sore dalam minggu yang sama, jadi waktu tinggal hewan ternak di UPTD pasar ternak Palangki dapat diasumsikan menjadi satu hari.

\subsection{Menghitung Potensi Biogas}

Satu ekor sapi atau kerbau mampu menghasilkan kotoran sebanyak $25 \mathrm{~kg} / \mathrm{hari}$, pada UPTD pasar ternak Palangki, dari data tahun 2010 - 2015, jumlah ternak terbanyak dalam satu bulan terdapat pada tahun 2011 yaitu pada bulan Oktober, pada tahun itu dalam satu bulan hewan ternak pernah mencapai sebanyak 6014 ekor, jadi rata-rata setiap minggunya pada bulan itu mencapai 1504 ekor, maka kotoran yang dihasilkan ternak ini sebanyak $37600 \mathrm{~kg} /$ minggu, sehingga besar potensi biogas yang dapat dihasilkan adalah sebesar $37600 \mathrm{~kg}$ x 0,04= $1504 \mathrm{~m}^{3} /$ minggu.

\subsection{Menghitung Volume Reaktor Biogas}

Kotoran hewan yang telah diperoleh tadi harus ditambahkan air sebelum masuk biodigester agar bakteri dapat tumbuh dan berkembang dengan optimum. Perbandingan komposisi antara kotoran hewan dengan air adalah 1:1. Dengan demikian, jumlah air yang ditambahkan adalah sebanyak 37600 $\mathrm{kg}$, jadi jumlah massa total larutan kotoran padat (mt) adalah $75200 \mathrm{~kg}$, maka untuk memperoleh volume larutan kotoran (Vf) adalah $75200 \mathrm{~kg} / 1000 \mathrm{~kg} / \mathrm{m}^{3}=75,02 \mathrm{~m}^{3}$. Sehingga untuk menentukan volume biodigaster $(\mathrm{Vd})$ adalah $\mathrm{Vd}=\mathrm{Vf}$.tr, $\operatorname{tr}$ adalah waktu penyimpanan di reaktor biogas, penyimpanan ini tergantung dari masuknya bahan biogas kedalam reaktor, sedangkan di UPTD Palangki dalam satu minggu hanya satu hari yang menghasilkan kotoran ternak.
Jadi, volume biodigaster yang sesuai dengan UPTD pasar ternak Palangki berdasarkan kapasitas maksimal UPTD dalam satu minggu ( kapasasitas maksimal pasar ternak yang hanya mampu menampung hewan \pm 1600 ekor/ minggu) dan juga memperhatikan kebutuhan serta biaya, jadi reaktor yang dipakai adalah dengan kapasitas $8 \times 30 \mathrm{~m}^{3}$ (Toren air yang ada dipasaran).

\subsection{Menentukan Tipe Reaktor Biogas}

Untuk menentukan ini perlu pertimbangan - pertimbangan teknis dan ekonomis dalam menetukan tipe reaktor yang akan dibuat, hasil identifikasi masalah dengan cara studi literatur, konsultasi teknis dan kunjungan lapangan diperoleh kesimpulan bahwa bahwa reaktor tipe fixed dome dipilih untuk dibuat. Bebarapa alasannya adalah : (a) Umur ekonomis dapat mencapai 20-25 tahun, (b) Terbuat dari bahan - bahan lokal, (c) Kontruksi berupa dome sehingga mampu menahan beban baik didalam maupun diatas permukaan tanah, (d) Kontruksi didalam permukaan tanah sehingga kestabilan suhu dapat terjamin, (e) Penghematan penggunaan lahan, (f) Operasional alat mudah dilakukan, (g) Perawatan relative lebih mudah dan murah ( Jan Lam,2005 )

\subsection{Detail Desain Biodigaster ( Reaktor Biogas )}

Reaktor biogas UPTD Pasar Ternak Palangki terdiri dari beberapa komponen pendukung, seperti : saluran masuk slurry (inlet), saluran keluar residu (outlet), katup pengaman tekanan (water trap) dan saluran gas. 


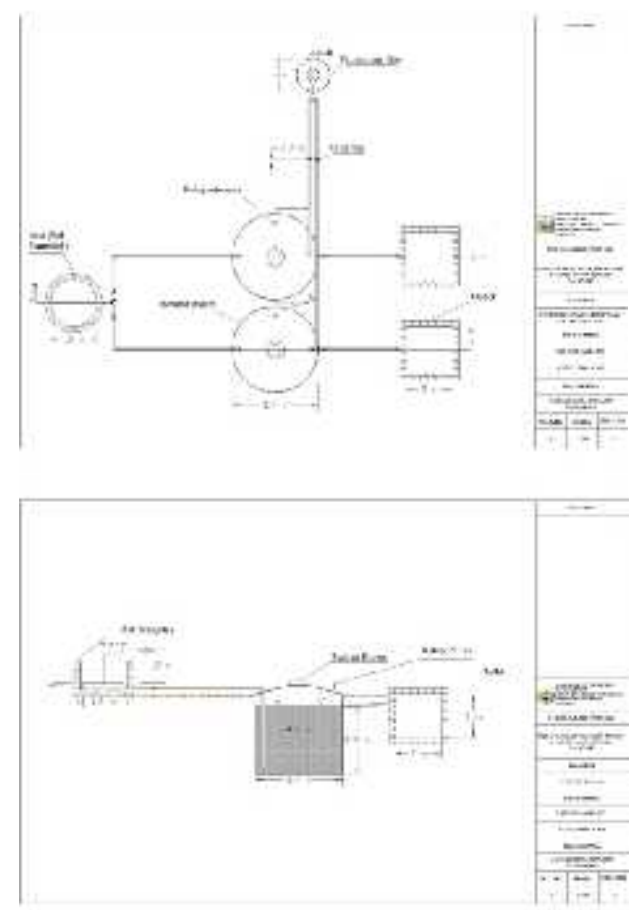

Gambar 1. Detail desain reaktor biogas

\subsection{Rencana Anggaran Biaya Biodigaster}

Rincian Anggaran Biaya (RAB) adalah suatu dokumen yang berisi rincian komponen-komponen masukan (input) dari sebuah kegiatan serta besaran biaya dari masing-masing komponen. RAB merupakan penjabaran lebih lanjut dari unsur perkiraan biaya dalam Kerangka Acuan Kegiatan (Term Of Reference).

Dalam pembuatan reaktor biogas di UPTD Pasar Ternak Palangki juga diperlukan RAB agar dapat memperkirakan besaran biaya, ditabel bawah ini akan menjelaskan RAB untuk UPTD Pasar Ternak Palangki.

Tabel 1. Rencana Anggaran Biaya Pembuatan Reaktor Biogas di UPTD Pasar Ternak Palangki
Tabel 1. Rencana Anggaran Biaya Pembuatan Reaktor Biogas di UPTD Pasar Ternak Palangki

\begin{tabular}{|c|c|c|}
\hline 10 & 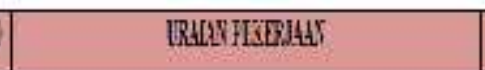 & 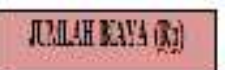 \\
\hline 1 & 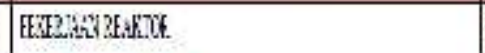 & $1530 \%$ \\
\hline & 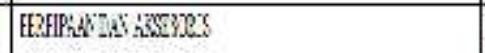 & 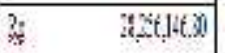 \\
\hline ! & 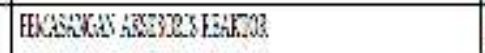 & 505151 \\
\hline & 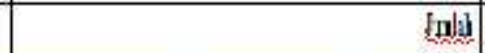 & 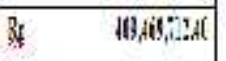 \\
\hline & fules & HISTH2 \\
\hline & Julitiol & 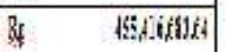 \\
\hline & Bhisb & 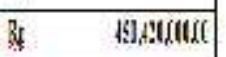 \\
\hline
\end{tabular}

\section{KESIMPULAN}

Pada Penelitian Studi Perancangan Reaktor Biogas di UPTD Pasar Ternak Palangki didapatkan hasil Kesimpulan sebagai berikut :

1. Berdasarkan Data dari UPTD Pasar Ternak Palangki, luasnya areal UPTD ini berbanding lurus dengan masukknya hewan ke UPTD ini yang mencapai 6014 ekor dalam satu bulan, jadi dapat diperkirakan potensi biogas yang dihasilkan pada minggu itu mencapai $1504 \mathrm{~m}^{3}$.

2. Berdasarkan kapasitas maksimal daya tampung hewan masuk UPTD Pasar Ternak Palangki, reaktor yang sesuai adalah dengan ukuran $8 \times 30.000 \mathrm{~L}$.

3. Berdasarkan perhitungan RAB untuk pembuatan reaktor di UPTD Pasar Ternak Palangki mencapai Rp 450.420.000.

\section{DAFTAR PUSTAKA}

Aguilar, FX., (2001), How to install a polyethylene biogas plant, Proceeding of the IBSnet Electronic Seminar, (The Royal Agricultural College, Cirencester, UK. 5-23 March 2001) 
Garcelon, J., Clark, J., Waste Digester Design, Civil Engineering Laboratory Agenda, University of Florida

Hambali, Erliza dkk. 2007. Teknologi Bioenergi. Jakarta: Agro Media Pustaka

Karim, FX (2005), Anaerobic digestion of animal waste: Waste strength versus impact of mixing, Bioresource Technology, 96, 1771-1791

Jan Lam. 2005. Evaluation Study for Biogas Plant Designs. Final Report of SNV(Netherlands Development Organization) Cambodia

Paimin, Ferry, B. 1995. Alat Pembuatan biogas Dari Drum. Jakarta: Penebar Swadaya.

Setiawan A. I. 2002. Memanfaatkan Kotoran Ternak. Jakarta : PT. Penebar Swadaya.

Simamora, S. et al. 2006. Membuat Biogas Pengganti Bahan Bakar Minyak Dan Gas Dari Kotoran Ternak. Jakarta: Agro Media Pustaka.

Wahyuni, Sri. 2009. Biogas. Jakarta: Penebar Swadaya. 